\title{
The Supportive Roles of Adults in Designing with Young Deaf Children
}

\section{Jessica Korte}

School of Information Technology and Electrical Engineering (ITEE), The University of Queensland, Australia.

j.korte@uq.edu.au

Involving users in the research and design of new technologies is particularly relevant for groups affected by digital exclusion and lacking in cultural power, such as people with disabilities, people from cultural minorities, and children. Design with young Deaf children lies at the intersection of these three groups, as the medical community defines physical deafness as a disability; Deaf communities around the world identify as minority cultural groups with their own languages; and young children traditionally lack power in interactions with adults. Deaf children bring particular needs, abilities and experiences related to their youth, physical deafness and cultural Deafness to the technology design process, making their involvement in design vital. Their involvement presents a unique set of challenges and ethical considerations, including matters of consent and behaviour management. Adult involvement in supportive roles can facilitate young Deaf children's involvement in design activities and address some of the challenges of designing with Deaf children.

This article presents a case study that involved young Australian Deaf children as design partners, with their family members and Deaf and hearing education professionals in supportive roles, for the purpose of providing recommendations to researchers and designers who wish to

Korte, J. (2018). The supportive roles of adults in designing with young deaf children. The Journal of Community Informatics, 14(1), 82--104.

Date submitted: 2018-10-01. Date accepted: 2018-10-15.

Copyright (C), 2018 (the author as stated). Licensed under the Creative Commons AttributionNonCommercial-ShareAlike 2.5. Available at: www.ci-journal.net/index.php/ciej/article/view/1457 
undertake similar design activities with young Deaf children and supportive adults. The case study involved a series of 30-minute design sessions with four Deaf children (ages 3-5). Reflections on this case study will discuss the roles adult design team members took throughout the design sessions, the benefits and challenges of involving adults as members of design teams with young Deaf children, and ethical considerations to be addressed when designing with young Deaf children in design teams. The article concludes with recommendations for researchers and designers conducting design sessions with young Deaf children and adult supporters, so that young Deaf child designers are well-supported and have the freedom to explore their preferences, desires, requirements, and to contribute to design solutions.

\section{Introduction}

In a world in which technology has become ubiquitous, it is important that the design of technologies considers the needs and abilities of marginalised groups, or they will be left behind, in a phenomenon known as digital exclusion. Design philosophies such as user-centred design and participatory design have emphasised the importance of identifying, designing for and designing with end users (Druin, 2002; Iivari \& Iivari, 2011); but the people who are most in need of specialised support and consideration in technology design are also the ones most likely to be excluded (Clayton \& Macdonald, 2013; Roy Morgan Research, 2016). Young Deaf children represent one group that faces digital exclusion, as they fall at the intersection of three identities that lack traditional power: the medical community defines physical deafness as a disability; Deaf communities around the world identify as minority cultural groups with their own signed languages; and young children traditionally lack power in interactions with adults. Deaf children also have unique needs when it comes to technology (Potter, Korte $\&$ Nielsen, 2014), and their input is needed to ensure new technologies consider their needs.

The literature on designing with children with 'special needs' (Guha, Druin \& Fails, 2008) or across cultures (Kam et al., 2006) recognises that additional adult support is necessary; at the bare minimum as translators when a language is not shared by all members of a design team. This article presents a case study of a series of design sessions in which young Deaf children aged 3-5 years, their family members, and Deaf and hearing educational professionals undertook design activities to the goal of creating a design method. From this case study, we will present recommendations for researchers and designers who wish to work with Deaf children and adults in technology design.

\section{Identity Representation and Language Conventions}

Within this article, the terms Deaf and deaf will be used according to Deaf cultural norms and the Co-operation Agreement between World Federation of the Deaf and the International Federation of Hard of Hearing People. Capitalised 'Deaf' refers to cultural 
Deafness and identity. Lower-case 'deaf' refers to physical deafness. This article will use terms such as 'Deaf children', rather than the forms 'children who are Deaf', in recognition of the Australian Deaf community's preference for identify first language. Identity first language will also be used when discussing literature focusing on other disability/identity groups, such as 'Autistic children', even when the original literature has used person-first terminology, such as 'child with ASD', as this is expressed as the preference by Autistic self-advocacy groups (Autism Mythbusters, n.d.; Brown, 2016).

Where direct translations of Australian Sign Language (Auslan) signs are included, they will be indicted as SMALL CAPS glosses, as translations between Auslan and English are not exact. Some Auslan signing will be paraphrased for translation. All written translations have been undertaken by the author for data analysis purposes, based on an elementary proficiency in Auslan (Interagency Language Roundtable, 2011a; 2011b) and supported by live interpretation by Deaf and hearing educational professionals during the design sessions.

\section{Literature Review}

\section{Digital Exclusion and Participatory Design with Deaf Children}

Interactive technologies have become ubiquitous in everyday life. User-centred and participatory design approaches have been developed and used since the 1980s to improve the usability of technologies and responsiveness of designs to users' needs and abilities (Druin, 2002; Iivari \& Iivari, 2011). However, even with user involvement in participatory design, decisions about how technologies are used and designed often focus on the social majority, meaning groups that face social exclusion also face higher risks of experiencing digital exclusion (Clayton \& Macdonald, 2013; Roy Morgan Research, 2016). Two groups that are likely to experience social, and therefore digital, exclusion, are people with disabilities and people from cultural minorities (Bathgate \& Romios, 2011; Vinson, 2009).

Children have also historically been overlooked in terms of inclusion in participatory design, although this has been changing since the mid-1990s (Druin, 2002), and childcomputer interaction is now seen as a field of research in its own right. Adults can be resistant to working with children as equal design partners, even while recognising the importance of acknowledging and incorporating children's unique insights into the design of new technologies (Druin, 2002; Scaife \& Rogers, 1999). Based on a historical review of children's involvement in technology design, Druin proposed a hierarchy of design roles in which children act when involved in technology design with adults: user, tester, informant, design partner, and software designer (Druin, 2002; Guha, Druin \& Fails, 2013). As users, children have no direct involvement in technology design, but may be observed by adult designers. As testers, children interact with milestone or prototype technologies to give feedback that may be used to alter relatively minor aspects of the final products. As informants, children give their input at times when it 'is considered to be most valuable' (Guha et al., 2013, pp. 57-58), but are not actively involved in the design process, and their contributions are filtered through the decisions of adult designers. The informant role covers a wide spectrum of involvement, from 
children providing direct input to a project (Korte, 2012; Scaife \& Rogers, 1999), to children sharing their understanding of topics relevant to the design project's aim (Bekker, Beusmans, Keyson \& Lloyd, 2003; Dindler, Eriksson, Iversen, Lykke-olesen \& Ludvigsen, 2005; van Doorn, Gielen \& Stappers, 2014; van Doorn, Stappers \& Gielen, 2013), to children inspiring adult designers through their actions (Druin, 1999; Druin et al., 1999; Larsen \& Hedvall, 2012). Informants' input may reveal new ideas and information, or confirm the decisions already made by the adult design team (Druin, 2002; Scaife \& Rogers, 1999). Children who are design partners work as equal partners with adult designers, making significant contributions throughout the entirety of the design process (Druin, 2002; Guha et al., 2013). As software designers, children work to design new technologies without major adult assistance, although they may have adult support (Guha et al., 2013; Harel, 1991; Kafai, Ching \& Marshall, 1997).

A number of design approaches have been developed to involve children in the design of new technologies at each of these design roles. The most famous of these is Druin's Cooperative Inquiry, in which children are design partners in intergenerational design teams (Druin, 1999). However, children with disabilities, especially those with a communication gap, may face exclusion from higher levels of involvement, as they require extra support to facilitate their full participation at higher design roles, such as specialised technology or adult assistance (Allsop, Gallagher, Holt, Bhakta \& Wilkie, 2011; Guha et al., 2008; Rabiee, Sloper \& Beresford, 2005). 'Vanilla' versions of design methods intended for designing with school-aged children without disabilities do not provide sufficient support without modification (Guha et al., 2008). Young children face similar, though less significant, hurdles to their design involvement, as they may struggle with aspects of design activities, such as abstract communication, ideation, collaboration, and writing (Druin, 2005; Druin et al., 1999; Farber, Druin, Chipman, Julian \& Somashekhar, 2002).

Cross-cultural design with children also requires extra considerations and support. The obvious barrier to communication is language, and interpreters and/or translators are usually included in situations in which there is not a shared language between the children and the adult designers (Antle \& Bevans, 2012; Kam et al., 2006). Other differences that have been seen in the literature, and that should be considered, are cultural norms and values, educational approaches, and relative exposures to technology and other resources (Antle \& Bevans, 2012; Hamidi, Saenz \& Baljko, 2014; Kam et al., 2006; Korte, Potter \& Nielsen, 2017).

In the case of Deaf children, the support required to facilitate their involvement in participatory design is multifaceted. In addition to the resistance to collaboration with children displayed by some adults, physical deafness is medically recognised as a disability, and cultural Deafness represents a linguistic and cultural divide (Korte et al., 2017). Physical and cultural Deafness contribute to unique characteristics of Deaf children, which influence their need for support during participatory design activities (Potter et al., 2014). Deaf children tend to have slower language acquisition, lower literacy levels, and slower academic development than their hearing peers or the children of Deaf parents (Masataka, 2000; Sass-Lehrer \& Bodner-Johnson, 2003; Traxler, 2000). This can lead to behavioural and attention problems, and reduced social 
and emotional development compared to their peers (Barker et al., 2009; Calderon \& Greenberg, 2003; Mitchell \& Quittner, 1996; Sass-Lehrer \& Bodner-Johnson, 2003).

Culturally Deaf children use visual-spatial cognitive processing (Ebrahim, 2006), and develop more sensitive peripheral vision (Hirshorn, 2011). These factors mean Deaf children can be more sensitive to visually distracting stimulus (Mitchell \& Quittner, 1996). Norms of Deaf culture have an impact on communication with Deaf children; relative locations of communicators, and the getting and retaining of visual attention are important considerations during interactions with Deaf people (Korte et al., 2017). Deaf children are creative communicators when they are motivated to communicate (Potter et al., 2014; Williams, 2004).

These differences can all impact participatory and collaborative design approaches undertaken with Deaf children. Designing with Deaf children requires greater levels of adult involvement than designing with hearing children of the same age. However, with appropriate support, they can be valuable contributors to the design of technologies (Guha et al., 2008; Potter et al., 2014).

\section{Adult Involvement in Design with Children: Proxies, Partners and Supporters}

In designing technologies for and with children, the terms 'proxy' and 'partner' seem to be at opposite ends of a spectrum of children's involvement. Adults acting as proxies in design activities speak for the children, offering their insights into the needs and abilities of particular groups of children, usually based on expertise or training in child development, as in the case of psychologists or teachers (Guha et al., 2013), or close personal experience with children in the target demographic, as in the case of family members, friends or carers (Brereton, Sitbon, Abdullah, Vanderbert \& Koplick, 2015; Tan, 2017). Consulting adult proxies in lieu of children is more common when designing for children with whom communication is difficult, such as those with disabilities (Allsop et al., 2011; Allsop, Holt, Levesley \& Bhakta, 2010). Another common use of proxies is that proxies such as family members, teachers, carers, or other experts, may be involved in information gathering and/or the initial design of a technology; members of the target audience are then involved as testers or informants in evaluating and elaborating on future iterations of the technology (Allsop et al., 2011; Brereton et al., 2015; Tan, 2017). The philosophy of the field of child-computer interaction is that it is not sufficient to work solely with proxies, even for 'difficult' populations of children (Guha et al., 2013), as children have unique abilities and understandings of their abilities and the realities of being a child in the modern world, which adult proxies cannot capture; this may be even more true for children with disabilities or communication difficulties, who may self-identify differently than their carers or parents might describe them (Allsop et al., 2011; Guha et al., 2013; Potter, Korte \& Nielsen, 2011; Scaife \& Rogers, 1999).

In contrast, and as described above, adults partnering with children in design activities work with children as their equals, contributing to designs through collaboration and elaboration of ideas proposed by other design team members (Druin, 2002; Guha et al., 2013). 
A third role underlies the spectrum, that of supporters. In any level of involvement, children may be supported in design activities by adults. Guha, Druin and Fails codified this in their inclusionary model for designing with and for children with special needs (2008), which advocated for involving children with 'special needs' in design activities by considering the desired level of children's involvement; the nature and severity of their disability; and the availability and intensity of support that could be provided. Greater levels of support are required to enable children with disabilities to participate in design activities at a greater level of involvement. Such support is sometimes technological, such as providing accessibility hardware or assistive technologies (Allsop et al., 2011); but often extra adult assistance during design activities is required (Allsop et al., 2011; Guha et al., 2008; Korte et al., 2017). Such assistance may include interpretation to bridge language barriers (Antle \& Bevans, 2012; Guha et al., 2008; Kam et al., 2006; Korte et al., 2017), or individualised support from adults to support the children in staying focused, or undertaking activities they would struggle to complete alone, from reading and writing, through to focus and memory (Allsop et al., 2011; Guha et al., 2008). In some roles, such as interpreters, those adults require specialised skills and training; however, in many cases, specialised training is not required (Guha et al., 2008).

\section{Adult roles through children's eyes}

In identifying the four design roles for children, Druin also identified that there were three dimensions to each role. One of those dimensions was the children's relationship to 'designers' - meaning adults. The relationship is summarised in Table 1, below.

Table 1: The relationship children have to adult designers at each level of design involvement, excluding software designer. Adapted from Druin (2002, p. 4).

\begin{tabular}{|l|c|c|c|c|}
\hline \multirow{2}{*}{ Role of children } & \multicolumn{4}{l|}{ Relationship to adult designers } \\
\cline { 2 - 5 } & Indirect & Feedback & Dialogue & Elaborate \\
\hline User & $\mathrm{X}$ & & & \\
\hline Tester & $\mathrm{X}$ & $\mathrm{X}$ & & \\
\hline Informant & $\mathrm{X}$ & $\mathrm{X}$ & $\mathrm{X}$ & \\
\hline Design partner & $\mathrm{X}$ & $\mathrm{X}$ & $\mathrm{X}$ & $\mathrm{X}$ \\
\hline
\end{tabular}

Table 1 can be 'flipped', to see through the children's eyes what interactions adults are likely to have when designing with and for children in each design role. This relationship is shown in Table 2, with justifications from the literature provided below. 
Table 2: Adult roles when interacting with children. Adapted from Korte (2017, p. 75).

\begin{tabular}{|c|c|c|c|c|c|}
\hline \multirow{2}{*}{$\begin{array}{l}\text { Adult } \\
\text { interactions } \\
\text { with children }\end{array}$} & \multicolumn{5}{|c|}{ Role of children } \\
\hline & User & Tester & Informant & $\begin{array}{l}D \text { e s } i g n \\
\text { partner }\end{array}$ & $\begin{array}{l}\text { Software } \\
\text { designer }\end{array}$ \\
\hline $\begin{array}{l}\text { Collaboration } \\
\text { or partnership }\end{array}$ & & & & $\mathrm{X}$ & \\
\hline $\begin{array}{l}\text { Supporting and } \\
\text { facilitating }\end{array}$ & & & $\mathrm{X}$ & $\mathrm{X}$ & $\mathrm{X}$ \\
\hline $\begin{array}{l}\text { Interacting with } \\
\text { children's world }\end{array}$ & & & $\mathrm{X}$ & & \\
\hline $\begin{array}{l}\text { Seeking } \\
\text { children's } \\
\text { advice }\end{array}$ & & & $\mathrm{X}$ & & \\
\hline $\begin{array}{l}\text { Seeking } \\
\text { children's } \\
\text { opinions }\end{array}$ & & $\mathrm{X}$ & $\mathrm{X}$ & & \\
\hline Setting tasks & & $\mathrm{X}$ & $\mathrm{X}$ & & $\mathrm{X}$ \\
\hline $\begin{array}{l}\text { Providing } \\
\text { technologies }\end{array}$ & & $\mathrm{X}$ & $\mathrm{X}$ & & \\
\hline Observing & $\mathrm{X}$ & $\mathrm{X}$ & $\mathrm{X}$ & & \\
\hline
\end{tabular}

Druin, in her review of the history of designing with children, found that observation was a core part of many design methods with children as users (2002).

In addition to observing children, adults designing with children as testers have more interactions with the children. A core theme at this level is providing technologies for children to interact with - usually prototypes - sometimes with set tasks to be completed, and often seeking feedback from the children (Barendregt, Bekker \& Baauw, 2008; Druin, 2002).

The children's role as informant can be seen to have three overall approaches: children providing design inspiration; children exploring and explaining subject matter; and children providing design direction. Design methods in which children provide design inspiration can have a great deal of overlap with those in which children are users or testers, as the children's everyday experiences or interactions with technologies act as springboards for adult designers' ideation. This can be seen in Druin's Collaborative Inquiry approach, in which designers focus on experiencing the children's world through the children's eyes, to better understand the children's needs and desires (Druin, 1999; Druin et al., 1999); or the SID for Snoezelen method, in which children with disabilities interacted with technological artefacts to inspire adult designers to create new technologies (Larsen \& Hedvall, 2012). What distinguishes this informant role from that of children as users or testers is the underlying philosophy that recognises that the children have their own ideas, which cannot be identified if adult proxies are the only informants in design activities. In SID for Snoezelen, for example, the children 
were seen to interact with technologies in ways that adult designers had not previously considered (Larsen \& Hedvall, 2012), sparking new directions in technology design, rather than prompting minor modifications to an existing prototype as would have been the case if the children were testers.

The other two approaches of children as informants are more clearly distinct from the less involved roles, as adult designers tend to support and facilitate children in undertaking activities that inform the format or content of new technologies. This may involve testing or creating prototypes, as seen in Informant Design (Scaife \& Rogers, 1999); researching a new technology's subject matter, as seen in the KidReporter project (Bekker et al., 2003); or educating someone on a technology's subject matter, as seen in the Mission From Mars project (Dindler et al., 2005).

When children are design partners, the relationship between children and adults is intended to be one of equal collaboration, with children and adults equally proposing new ideas and elaborating on existing ideas (Druin, 2002). In Druin's writings, children working as design partners may interact with children involved in other design roles, such as user or tester (Druin, 1999).

When children are software designers, adults tend to set the task of what they are developing - who the audience is, what the subject matter is, what type of software is to be developed - and then provide varying levels of support and facilitation (Harel, 1991; Harel \& Papert, 1990; Kafai et al., 1997).

It is worth noting that, in all cases, adults are expected to maintain traditional 'adult responsibilities' for issues such as safety, and mediating conflicts if they arise (Guha et al., 2008; 2013).

\section{Parental involvement in design with children}

There are few examples in the research literature of parents working with their children as supporters, and even fewer of parents working with their children as equal design partners. A possible contribution to the lack of parental involvement in design with children is that many design projects undertaken with children occur in a school context (Allsop et al., 2011; Harel, 1991; Harel \& Papert, 1990; Kafai et al., 1997; Korte, 2012; Scaife \& Rogers, 1999; Scaife, Rogers, Aldrich \& Davies, 1997), which would limit the ability of parents to be involved in the design activities. However, even in situations that involved interacting with children in home environments, such as the Embodied Narratives project (Giaccardi, Paredes, Díaz \& Alvarado, 2012) or Contextual Inquiry (Druin, 1999) parents do not often seem to have been involved.

Read et al.'s Web Site Design Day project (2002) provides an example of parents taking a supportive role while children are design partners or informants, as a number of 'parent helpers' acted as facilitators in a workshop in which children designed a new website for their school. However, Read et al. do not discuss their involvement or contribution to the design activities (2002).

Brereton et al.'s MyCalendar project for Autistic children may provide an example of parents and teachers acting as both supporters of their informant children, and proxy informants themselves (2015). The project initially involved parents, teachers and 
Autistic children in a pilot study that encouraged parents to treat their children as equals in allowing them to guide conversations supported by technology, inspired by the therapeutic Hanen Approach (Abdullah \& Brereton, 2012). These interactions inspired the MyCalendar technology, and a larger project involved parents, teachers and Autistic children as informants in 'design after design'. They interacted with the prototype MyCalendar technology, to discover new use cases for that technology, which had been designed by expert proxies and one parent of an Autistic child, also acting as a proxy. This 'design after design' resulted in teachers and parents supporting the children in creating new uses of the technology, and developing their own new uses, which informed future development of the technology (Brereton et al., 2015).

It can be seen from these interactions that there may be potential for parental involvement in design sessions with children, but they have not been explored in depth.

\section{Case Study: YoungDeafDesign}

\section{Case Study Overview}

The research project undertaken in the case study involved a series of 25 exploratory design sessions undertaken over a five-month period, with a design team of Deaf children and Deaf and hearing adults, at an Education Queensland Early Childhood Development Program in Queensland, Australia. The project was undertaken as the author's PhD research project (Korte, 2017). The primary goal of the research project was the creation of a design approach for working with young Deaf children, titled YoungDeafDesign. It was intended that young Deaf children would be able to work with adults as design partners using YoungDeafDesign. To support this goal, the design sessions were modelled on Druin's bags of stuff technique, which is a low-tech prototyping approach using art supplies (Druin, 2010; Guha et al., 2013). Each session involved some members of the design team using expressive materials to explore an idea or theme (such as emotions or people) or solving a problem (such as blowing up a balloon through a straw). These activities were intended to be indicative of the types of creative interactions seen in bags of stuff, which enable children and adults to solve problems and design technologies together.

The design team was composed of:

- four Deaf children aged 3-5, who will be referred to as Participant D (female, 4.5 years), Participant E (female, 4 years), Participant $\mathrm{S}$ (female, 3.5 years) and Participant SH (male, 3.7 years), each of whom attended classes at the Early Childhood Development Program;

- one Deaf and one hearing staff member of the Early Childhood Development Program (referred to as the Auslan Language Model and the Educational Interpreter throughout this article), who acted as sign language interpreters and design team members in their own right;

- Participant D's mother and both of Participant E's parents, who were not initially intended to join the design sessions, but who became involved to support their children and acted as design team members in their own right; and 
- the author as Lead Designer.

There was also an adult observer present in each design session, who took notes of events and interactions as they occurred. Participant S's mother and Participant SH's carer observed a handful of sessions each.

Every design session was attended by at least one child and the lead designer. Most design sessions were attended by multiple children and at least two adult design team members. No session was attended by all members of the design team, although there were sessions that all four children attended.

All of the children were learning Auslan (Australian Sign Language) and English at the Early Childhood Development Program. Participant S and Participant SH were also learning Arabic and Dari, respectively, at home. Participant S had Down Syndrome, and Participant D had been diagnosed with an intellectual disability. Comorbid medical conditions are not uncommon for deaf people, with Gallaudet University reporting that $38.9 \%$ of deaf children surveyed in 2009-2010 had 'additional conditions' alongside their deafness (Gallaudet Research Institute, 2011, p. 12). None of the children were fluent in Auslan, and communicated in a combination of Auslan key-signing and nonverbal forms of communication, including acting out things they wished to communicate and expressive body language.

Participant D's mother and Participant E's parents all knew some Auslan, and, importantly, were very familiar with their child's communication style. The lead designer had an elementary proficiency in Auslan, but was not familiar with cultural norms for communicating with young Deaf children.

\section{Case Study Extract}

Participant $E$ was interacting with design artefacts that her parents had made from chenille sticks when a staff member from the school picked up a packet of plasticine and waved to get Participant E's attention. The staff member signed to her, LOOK, then signed and mimed kneading and rolling the plasticine. She then pointed to the animals depicted on the packet, and signed the name of each one: CROCODILE, BEETLE.... LOOK, she signed again, and mimed opening the packet. Participant E nodded, so she opened the packet and asked Participant E which colour she wanted. Participant E pointed to one, and the staff member asked her to sign the colour-sign. The staff member then gave her the plasticine, and she showed it to her father. The staff member got her attention again, and signed to ask if her father wanted one, and what colour to give him? Participant E thought about this, until her father tapped her on the shoulder and signed PINK. Participant E's father, the staff member, and the lead designer then spent some time showing Participant E different ways of using plasticine. Later in the design session, after a packet of googly eyes had been introduced as an expressive material, Participant E's father created a plasticine fish, and put it on the table. Participant E picked it up and tried to cut it with scissors. The lead designer signed, NO!, so Participant E hesitated. She put the plasticine fish into a plastic bowl that she had earlier 'filled with water' from a toy sink in the design room. She happily signed FISH, and began dropping 
small pieces of plasticine into the bowl, signing FOOD. (Extract from the second design session.)

\section{Children's Role in YoungDeafDesign}

Despite the goal of young Deaf children being design partners, in the final YoungDeafDesign method the children's design role fell between that of informant and design partner when considered in terms of the children's relationship to adult members of the design team (see Table 3).

Table 3: A comparison of the relationship children have to adult designers in each design role (Druin, 2002) with the children's role in YoungDeafDesign (Korte, 2017)

\begin{tabular}{|l|c|c|c|c|}
\hline \multirow{2}{*}{ Role of children } & \multicolumn{4}{|l|}{ Relationship to adult designers } \\
\cline { 2 - 5 } & Indirect & Feedback & Dialogue & Elaborate \\
\hline User & $\mathrm{X}$ & & & \\
\hline Tester & $\mathrm{X}$ & $\mathrm{X}$ & & \\
\hline Informant & $\mathrm{X}$ & $\mathrm{X}$ & $\mathrm{X}$ & \\
\hline Design partner & $\mathrm{X}$ & $\mathrm{X}$ & $\mathrm{X}$ & $\mathrm{X}$ \\
\hline YoungDeafDesign & $\mathrm{X}$ & $\mathrm{X}$ & & $\mathrm{X}$ \\
\hline
\end{tabular}

Children and adults within the design sessions elaborated on each other's creations and games, exploring new ideas together in a way that Druin attributes only to the design partner role (Druin, 2002). The children also provided feedback - sometimes verbally, but often non-verbally - about design sessions, design session artefacts, and prototypes created based on earlier design session activities. Decisions about future directions for areas of exploration or problems to solve within the design sessions were made by adults based on the children's indirect communication - their demonstrated abilities and preferences. The gap between taking a full design partner role came from the children's lack of language fluency, which meant that it was not possible to hold abstract dialogues with the children, such as discussing their role in designing new technologies for other children. Therefore, children's role in YoungDeafDesign can be seen as more than informants, due to the elaboration with adults; however, it is also less than being full design partners, due to the lack of potential for dialogue.

\section{Adult Interactions in YoungDeafDesign}

A summary of which adults were involved in which design interactions during YoungDeafDesign has been provided in Table 4; each group of adults has been discussed in more detail below. 
Table 4: How adult roles were implemented in YoungDeafDesign.

\begin{tabular}{|l|l|}
\hline Adult interactions with children & Adults involved in YoungDeafDesign \\
\hline Collaboration or partnership & $\begin{array}{l}\text { Lead designer, Auslan Language Model, Participant } \\
\text { E's parents }\end{array}$ \\
\hline Supporting and facilitating & Lead designer, educational staff, parents \\
\hline Interacting with children's world & $\begin{array}{l}\text { Familiar adults (educational staff, parents) were } \\
\text { present to emotionally support the children. } \\
\text { An unintentional interaction with the children's world } \\
\text { was that some children brought toys from home, and } \\
\text { the design sessions were held in a room that had toys } \\
\text { from the school. The children incorporated the toys } \\
\text { into the design activities. }\end{array}$ \\
\hline Seeking children's advice & $\begin{array}{l}\text { Lead designer, Auslan Language Model, Participant } \\
\text { E's parents }\end{array}$ \\
\hline Seeking children's opinions & $\begin{array}{l}\text { Lead designer, Auslan Language Model, Participant } \\
\text { E's parents }\end{array}$ \\
\hline Setting tasks & Lead designer, educational staff, parents \\
\hline Providing technologies & Lead designer \\
\hline Observing & Observers \\
\hline
\end{tabular}

\section{Educational staff as sign language interpreters, supporters and partners}

The intended role of the Deaf and hearing Early Childhood Development Program staff members was as sign language interpreters and support assistants (Allsop et al., 2010). They would be able to contribute to the design sessions as design partners in their own right, while also acting to support the children's involvement in design sessions linguistically and practically.

As Auslan interpreters, they:

- interpreted signs for the children to understand; and

- interpreted the children's signing.

This was important, because even though the lead designer had learned some Auslan, she was not fluent, and there were situations where interpreters were needed to convey understanding between children and the lead designer. There was also an instance of confusion, in which Participant E tried to sign something, but neither the lead designer nor the Auslan Language Model was able to understand what she meant.

Having educational backgrounds and existing relationships with the children seem to have influenced the educational staff members' behaviours within the design sessions, because they also:

- educated children and the lead designer to increase sign vocabulary and clarity;

- educated children and the lead designer in Deaf cultural norms, which promoted communication; 
- encouraged the children to communicate using Auslan; and

- encouraged or instructed children to undertake the design session activities.

As noted, two Early Childhood Development Program staff members joined the design team. However, they had different levels of willingness to work with the children as equals. The Auslan Language Model, who attended the majority of sessions, seemed to see herself as a member of the design team, and was willing to work with the children as fellow designers in exploring and elaborating on their ideas. The Educational Interpreter, however, seemed to see her role as being only an interpreter and an educator.

As a support assistant and design team member in her own right, the Auslan Language Model:

- actively encouraged children's involvement in design session activities, especially when children were hesitant or unsure about particular activities;

- elaborated on the children's creations;

- created artefacts for the children to elaborate on;

- trained the children in the use of expressive materials with which they were unfamiliar;

- $\quad$ played games with the children utilising design session artefacts; and

- helped to build trust within the design team by being a 'familiar face' during unfamiliar activities.

\section{Children's parents as supporters and partners}

It was not originally intended that the children's parents become members of the design team; as discussed in the literature review above, in the majority of literature involving designing with children as design partners, parents are notably absent. However, their involvement had a number of positive effects:

- In early design sessions, Participant E and Participant D expressed nervousness about the design sessions, and were calmer and more engaged with their parents present, and with their parents' encouragement to become involved in the design activities.

- Participant E's parents acted as design team members in their own rights, creating artefacts, which the children iterated on through modification and/or game play.

- Participant D's mother, while not a fluent signer herself, was very familiar with Participant D's communication and vocabulary, and could interpret to and for her. She was also able to suggest alternative vocabulary that would be clearer (e.g. Auslan has several signs that mean LOVE; Participant D was more familiar with one than the others). 


\section{Lead designer as partner and supporter}

The lead designer set the subject or problem for each design session, and provided expressive materials that were appropriate to that subject or problem. She learned elementary Auslan before the sessions began, to facilitate communication with the child participants and members of the Deaf community, including the Deaf staff of the Early Childhood Development Program. Throughout the design sessions, she emphasised the equality inherent in the design partner role, and focused on supporting children in their choices of activities and explorations. She identified directions for explorations in future design sessions based on the children's preferred activities and themes. This included creating technological prototypes based on the creations and activities within the design sessions, and providing them for the children's feedback and elaboration.

\section{Observers}

Each design session was observed by one of two observers. The observers were not intended to interact with the children; however, some of the children chose to interact with the observers. Participant D greeted the observer when she entered the room in several design sessions. Participant S liked to show her creations to the observer, who reacted with impressed shock. This seemed to please Participant S, and may have helped to keep her focused on the design activities.

\section{Adults outside the design team}

The children were eager to show off their creations from the design sessions to adults outside the design team, and there were many instances in which one or more children ran out of the design session room to show a staff member or parent an artefact they had created or were playing with. This was usually greeted with praise and impressed looks, then the children were encouraged to return to the design session room.

\section{Lessons from the Case Study}

\section{Adults Managing Young Children's Behaviour vs Being Equal Partners}

Adult design team members played a role in managing the children's behaviour during the design sessions. In some cases, such as mediating disagreements over issues such as 'who gets the scissors next', or safety concerns such as telling Participant S not to place small objects into her mouth, these fall into the category of traditional adult responsibilities, acknowledged in the literature as remaining the purview of adults even when working with children as design partners or software designers (Guha et al., 2008; 2013).

Another type of behaviour management commonly seen in YoungDeafDesign was in helping the children to focus on the design activities. When the children were uncertain about joining in the activities, encouragement from the Early Childhood Development Program staff members or their parents would often get them to join in. This extended 
to adults who were not technically part of the design team, as there were situations in which the children wished to show off their creations to parents or to Early Childhood Development Program staff members who were not part of the design team. Those adults usually praised and interacted with the creations, and encouraged the children to return to the design session room and continue the activities.

There were situations in which adults' attempts to manage the children's behaviour demonstrated a lack of respect for the children as equal design partners, for example, when the Educational Interpreter picked up Participant D's hands to show her how to form signs, or when Participant D's mother took her hands away from a prototype while telling her to watch the lead designer's signed questions. In these situations, we see a trade-off between the adult's role as a design partner, in which they should be working with the children as equals, and their traditional roles as educators and parents, trying to promote 'good behaviour' - in this case, good communication behaviour, which did benefit the design sessions in other ways. This highlights an important consideration in forming a design team: adults' willingness to commit to the design sessions as members of the team, and their willingness to work with children in ways that are respectful, accepting, and promote equality. Participant E's parents strongly demonstrated this, as their actions within the design sessions promoted Participant E's involvement in the design sessions and created artefacts for further exploration and iteration. Participant D's mother demonstrated this in many, but not all, of her interactions within the design sessions, as shown in the example above.

\section{Known Adults Being Supporters and Partners Promoted Trust and Involvement}

The presence of known and trusted adults within the design team, be they parents or staff members of the Early Childhood Development Program, seemed to promote confidence in the children. As noted, in early design sessions, Participant E and Participant D in particular seemed uncertain about the design sessions, and reluctant to get involved in the design activities. Encouragement from their parents and the Auslan Language Model was needed to draw them into the activities. In addition, the Auslan Language Model and parents acted as trainers within the design sessions, showing children how to use materials they were unfamiliar with, and assisting with any difficulties they had. The lead designer also provided training and assistance, but in the earliest sessions, the children seemed more inclined to turn to adults they knew for help. Over the course of the design sessions, as the lead designer because more familiar, they were more comfortable learning from the lead designer and asking them for help.

Adults acting as design partners in their own rights also facilitated the children's involvement in the design activities, because they created design artefacts with the expressive materials, which the children interacted with and elaborated on. Many sessions had spontaneous games created by the children that utilised an adult's creation, such as Participant E feeding the fish her father had created, and that provided contextual information about how the children saw the design artefacts. They could also provide areas of interest to the children, which suggested new avenues for design activities and themes for exploration within the design sessions. 


\section{Ethical Considerations of Designing with Young Deaf Children}

Design approaches that treat children as design partners and informants draw from a philosophy of respecting the children's unique abilities, and the need to understand their abilities and needs from their perspective, to inform technology designs. This philosophy is also relevant in research. Traditional power imbalances between adults and children, between able and disabled people, and between dominant and minority cultures, must all be considered when conducting design and research activities with Deaf children.

Within the YoungDeafDesign project, ethical clearance was sought from the author's university. Within that process, there were two major threads of consideration: the benefits and risks posed by the project, and ethical informed consent.

Prior research on the impacts of design involvement on children had suggested that children benefited from high levels of involvement in design projects, with increased confidence, and increased communication, team working, and problem solving skills being identified as some of the positive outcomes (Druin \& Fast, 2002; Farber et al., 2002; Guha, Druin \& Fails, 2010; Harel, 1991; Harel \& Papert, 1990; Kafai et al., 1997; Knudtzon et al., 2003). Further research has since identified that there is also a significant risk of anxiety that is likely to be experienced by children at the start of design projects (Korte, Potter \& Nielsen, 2017b).

The risks identified through the ethical clearance process for the YoungDeafDesign process included recognition of the likelihood of anxiety, and of frustration that children might experience in trying to communicate across the communication gap. As seen, the presence of familiar adults was helpful in alleviating the children's anxiety and promoting their involvement in design activities. The inclusion of sign language interpreters and parents who were familiar with their children's communication styles helped to bridge the communication gap, although, as noted, it did not completely address it. A commitment by the lead designer to be aware of the children's non-verbal communication was also helpful, as the children's body language and expressions often communicated feelings of frustration that they could not express in signs. The ultimate example of such body language was that, when participants were no longer interested in a particular activity, they disassociated from it by moving away, or pushing away the materials involved in the activity. The presence of expressive materials themselves was also helpful in supporting communication, as children used the materials and design artefacts to augment their communication, and adults could use them as props to reinforce communication to the children.

Design and research projects that aim to create technologies for groups likely to be subject to digital exclusion may claim a benefit to the communities they are designing with, if and when their technologies become available. In the case of the YoungDeafDesign project, the creation of a design approach to support designing with young Deaf children was intended to enable the creation of better technologies for the Deaf community. 
From the perspective of informed consent, young children are not legally able to consent, so within the YoungDeafDesign project, consent was sought from first the Early Childhood Development Program, then the parents of the children involved. The informed consent pack provided to parents included a simple consent form for the children, with smiling and frowning faces to indicate the children's willingness or otherwise to participate in the design sessions. It was intended that parents should explain the project to their children, and the children would be able to mark their agreement to participate. However, all of the child consent forms were returned marked in pen, suggesting the parents filled them out. This may be due to the difficulties identified above in communicating abstract ideas to young Deaf children.

\section{Conclusion}

Participatory design approaches tailored to the needs and abilities of minority groups can help to address digital exclusion by providing avenues for supported involvement in design activities, thereby resulting in technologies that are accessible to those minority groups. One such group is young Deaf children, who fall at the intersection of three minority groups, and are therefore at high risk of digital exclusion: the Deaf community is a cultural minority; physical deafness is identified as a medical disability, and often has other comorbid conditions; and young children lack power in traditional relationships with adults. This article has focused on YoungDeafDesign, a new design approach created for conducting design activities with young Deaf children taking a role somewhere between informant and design partners, with educational professionals and parents acting in supporting and partner roles. Adult interactions with children in YoungDeafDesign spanned a wide range. Of particular note are the roles that the children's parents took, as the involvement of parents in design approaches in which children are design partners is noticeably lacking in the literature on design with children.

This conclusion will provide a number of recommendations for designers and researchers wanting to design with young Deaf children, based on the learnings from the case study. These recommendations will interleave the practical and ethical considerations addressed in this article so far.

\section{Sign Language Interpreters}

It is vitally important, when designing with young Deaf children, to have sign language interpreters to support communication between all members of the design team. This is not merely a practical consideration, but an ethical one. Without understanding the children's communication, their input into the design activities has not truly been gathered, and their perspective will not be addressed in the final design of new technologies. An inability to communicate can also cause frustration for children and adults alike. In the YoungDeafDesign case study, professional educators acted as sign language interpreters. An unexpected finding was that parents of young Deaf children could also act as sign language interpreters for their own children in some situations. Being familiar with their child's particular approaches to communication meant they 
could support one-on-one communication. I recommend that designers and researchers wanting to work with young Deaf children should also take steps to familiarise themselves with the children's sign language and Deaf cultural communication norms, as these will help to promote communication. Designers and researchers should further commit themselves to awareness of non-verbal communication, as young Deaf children are expressive and inventive communicators when motivated (Potter et al., 2014; Williams, 2004), and this provides another opportunity to understand them, their needs, and their abilities.

\section{Treating Children with Equality and Respect}

Professional educators and parents have the capacity to work with young Deaf children as equal design team members, and as supporters and facilitators of the children's involvement. In the YoungDeafDesign sessions, parents and educators encouraged children to get involved in the design session activities, trained them in ways of using unfamiliar materials, assisted them when they had difficulties, and created design artefacts that the children elaborated on and interacted with in ways that provided design information. However, professional educators and parents may maintain or revert back to their traditional teaching roles, undermining the equality and respect necessary to work with children as equal design partners. It can be a fine line, as certain adult responsibilities, such as addressing safety concerns and mediating disputes, remain as adult responsibilities despite the otherwise equal relationship expected in a design partnership. I recommend, therefore, that designers working with young Deaf children and adults should discuss the importance of equality and respect with adult design team members before beginning design sessions. Such discussions may help to remind adults about the need for respect and equality before they act 'like an adult', however further research is needed to confirm this.

\section{Mitigating Children's Anxiety}

Another ethical and practical consideration is that young Deaf children involved in design activities for the first time may experience anxiety. The presence and involvement of adults who were familiar to the children, both parents and educational professionals, helped to ease the children into design session activities, and helped to build trust between the children and the lead designer. We recommend that familiar adults should be involved in design sessions with young Deaf children, particularly early design sessions, to help ease any anxiety the children experience. From an ethical consideration, this can help to decrease any suffering such anxiety causes the children. From a practical standpoint, collaboration is more likely when the children trust the adults on the design team, and more useful design information will be generated to inform the design of new technologies.

\section{Children's Explicit and Implicit Consent-Giving}

In terms of informed consent, the ethical approach should include informing the children about the activities they are to be involved in, and seeking their personal 
consent. However, from a practical perspective, it was extremely difficult to communicate abstract ideas about designing new technologies to young Deaf children in the case study. I recommend that attempts should be made, with the assistance of adults familiar with the children and their styles of communication; however, we recognise that it will not always be possible to gain informed consent from the children. In this situation, it is important to work closely with adults such as parents and teachers to ensure the children's best interests are being addressed through involvement in design activities. I further recommend that if children demonstrate that they do not wish to be involved in a particular design activity or in design sessions overall, even after encouragement from trusted adults, this should be recognised as the child withdrawing their consent to be involved in the design activity or design sessions.

\section{Conclusion}

Involving young Deaf children in the design of new technology can have benefits for the children involved, and to the wider Deaf community, through the creation of technologies that enable their digital and social inclusion. It can also be rewarding for designers and researchers involved, as young Deaf children are innovative communicators with abilities and interests of their own. It is my hope that the recommendations and examples provided here assist other designers and researchers in working with this minority group. These recommendations may also be of use to designers and researchers working with other groups prone to digital exclusion, but further research is needed to confirm this.

\section{Acknowledgements}

I would like to thank Tan Ching Ying Michelle for being the inspiration behind this article. Thanks also to my PhD supervisors, Dr Leigh Ellen Potter and Dr Sue Nielsen, and to the staff and students of the Early Childhood Development Program for participating in my research. 


\section{References}

Abdullah, M. H. L., \& Brereton, M. (2012). A child led participatory approach for technologybased intervention. In E. Tunstall \& C. Mads (Eds.), In 2012 Participatory Innovation Conference Digital Proceedings (pp. 1-5). Melbourne, Australia: Swinburne University.

Allsop, M., Gallagher, J., Holt, R., Bhakta, B., \& Wilkie, R. M. (2011). Involving children in the development of assistive technology devices. Disability and Rehabilitation: Assistive Technology, 6(2), 148-156. Retrieved from http://informahealthcare.com/doi/abs/ $10.3109 / 17483107.2010 .510178$

Allsop, M., Holt, R., Levesley, M., \& Bhakta, B. (2010). The engagement of children with disabilities in health-related technology design processes: Identifying methodology. Disability and Rehabilitation: Assistive Technology, 5(1), 1-13. Retrieved from http:// informahealthcare.com/doi/abs/10.3109/17483100903323267

Antle, A. N., \& Bevans, A. (2012). Creative design: Exploring value propositions with urban Nepalese children. In A. Nijholt, T. Romão, \& D. Reidsma (Eds.), Advances in Computer Entertainment (pp. 465-468). Kathmandu, Nepal: Springer Berlin Heidelberg. Retrieved from http://link.springer.com/chapter/10.1007/978-3-642-34292-9_36\#page-1

Autism Mythbusters. (n.d.). Autistic vs. People with Autism. Retrieved from http:// autismmythbusters.com/general-public/autistic-vs-people-with-autism/

Barendregt, W., Bekker, M. M., \& Baauw, E. (2008). Development and evaluation of the problem identification picture cards method. Cognition, Technology \& Work, 10(2), 95105. Springer. Retrieved from http://www.springerlink.com/index/ 07T8315M671V4472.pdf

Barker, D. H., Quittner, A. L., Fink, N. E., Eisenberg, L. S., Tobey, E. A., \& Niparko, J. K. (2009). Predicting behavior problems in deaf and hearing children: The influences of language, attention, and parent-child communication. Development and Psychopathology, 21(2), 373-392.

Bathgate, T., \& Romios, P. (2011). Consumer participation in health: Understanding consumers as social participants. Institute for Social Participation Seminar Series.

Bekker, M. M., Beusmans, J., Keyson, D., \& Lloyd, P. (2003). KidReporter: A user requirements gathering technique for designing with children. Interacting With Computers, 15, 187-202. Retrieved from http://linkinghub.elsevier.com/retrieve/pii/ S0953543803000079

Brereton, M., Sitbon, L., Abdullah, M. H. L., Vanderbert, M., \& Koplick, S. (2015). Design after design to bridge between people living with cognitive or sensory impairments, their friends and proxies. CoDesign, 11(1), 4-20. Retrieved from http://eprints.qut.edu.au/ $78487 /$

Brown, L. (2016). Identity-First Language. Autistic Self Advocacy Network. Retrieved from http://autisticadvocacy.org/home/about-asan/identity-first-language/

Calderon, R., \& Greenberg, M. T. (2003). Social and emotional development of Deaf children: Family, school, and program effects. In M. Marschark \& P. E. Spencer (Eds.), Oxford Handbook of Deaf Studies, Language and Education (pp. 177-189). Oxford: Oxford University Press.

Clayton, J., \& Macdonald, S. J. (2013). The Limits of Technology. Information, Communication and Society, 16(6), 945-966.

Dindler, C., Eriksson, E., Iversen, O. S., Lykke-olesen, A., \& Ludvigsen, M. (2005). Mission from Mars - A method for exploring user requirements for children in a narrative space. Proceedings of the 2005 conference on Interaction Design and Children (pp. 40-47). 
Boulder, Colorado, USA. Retrieved from http://dl.acm.org/citation.cfm?id=1109546

van Doorn, F., Gielen, M., \& Stappers, P. J. (2014). Children as Co-Researchers: More than Just a Role-Play. Proceedings of the 2014 Interaction Design and Children conference (pp. 237-240). Aarhus, Denmark.

van Doorn, F., Stappers, P. J., \& Gielen, M. (2013). Design research by proxy: Using children as researchers to gain contextual knowledge about user experience. Proceedings of the SIGCHI conference on Human Factors in Computing Systems (pp. 2883-2891). ACM.

Druin, A. (1999). Cooperative Inquiry: Developing new technologies for children with children. Proceedings of ACM CHI 99 Conference on Human Factors in Computing Systems (Vol. 14, pp. 223-230). Pittsburgh, PA, USA: ACM. Retrieved from http://dl.acm.org/ citation.cfm? $\mathrm{id}=303166$

Druin, A. (2002). The role of children in the design of new technology. Behaviour and Information Technology, 21(1), 1-25. Taylor \& Francis. Retrieved from http:// www.tandfonline.com/doi/abs/10.1080/01449290110108659

Druin, A. (2005). What children can teach us: Developing digital libraries for children with children. The Library Quarterly, 75(1), 20-41. Retrieved from http://www.jstor.org/stable/ $10.1086 / 428691$

Druin, A. (2010). Children as codesigners of new technologies: Valuing the imagination to transform what is possible. New directions for youth development, 2010(128), 35-43. Retrieved from http://onlinelibrary.wiley.com/doi/10.1002/yd.373/abstract

Druin, A., Bederson, B., Boltman, A., Miura, A., Knotts-Callahan, D., \& Platt, M. (1999). Children as our technology design partners. In A. Druin (Ed.), The Design of Children's Technology (pp. 51-72). San Francisco, USA: Morgan Kaufmann. Retrieved from http:// drum.lib.umd.edu/handle/1903/947

Druin, A., \& Fast, C. (2002). The child as learner, critic, inventor, and technology design partner: An analysis of three years of Swedish student journals. International Journal of Technology and Design Education, 12(3), 189-213. Retrieved from http:// link.springer.com/10.1023/A:1020255806645

Ebrahim, F. (2006). Comparing creative thinking abilities and reasoning ability of Deaf and hearing Children. Roeper Review, 28(3), 140.

Farber, A., Druin, A., Chipman, G., Julian, D., \& Somashekhar, S. (2002). How young can our design partners be? Proceedings of the 2002 Participatory Design Conference (pp. 127131). Malmö, Sweden.

Gallaudet Research Institute. (2011). Regional and National Summary Report of Data from the 2009-10 Annual Survey of Deaf and Hard of Hearing Children and Youth. Washington, DC, USA.

Giaccardi, E., Paredes, P., Díaz, P., \& Alvarado, D. (2012). Embodied Narratives: A performative co-design technique. Proceedings of the ACM conference on Designing Interactive Systems (pp. 1-10). Newcastle, UK: ACM.

Guha, M. L., Druin, A., \& Fails, J. A. (2008). Designing with and for children with special needs: An inclusionary model. Proceedings of the 7th International Conference on Interaction Design and Children (pp. 61-64). ACM.

Guha, M. L., Druin, A., \& Fails, J. A. (2010). Investigating the impact of design processes on children. Proceedings of Interaction Design and Children (pp. 198-202). Barcelona, Spain: ACM.

Guha, M. L., Druin, A., \& Fails, J. A. (2013). Cooperative Inquiry revisited: Reflections of the past and guidelines for the future of intergenerational co-design. International Journal of 
Child-Computer Interaction, 1(1), 14-23. Elsevier B.V. Retrieved from http:// linkinghub.elsevier.com/retrieve/pii/S2212868912000049

Hamidi, F., Saenz, K., \& Baljko, M. (2014). Sparkles of brilliance: Incorporating cultural and social context in co-design of digital artworks. Proceedings of the 2014 Interaction Design and Children conference (pp. 77-84).

Harel, I. (1991). Children Designers: Interdisciplinary Constructions for Learning and Knowing Mathematics in a Computer Rich School. Norwood, New Jersey, USA: Ablex Publishing.

Harel, I., \& Papert, S. (1990). Software design as a learning environment. Interactive Learning Environments, 1(1), 1-32. Retrieved from http://www.tandfonline.com/doi/abs/ $10.1080 / 1049482900010102$

Hirshorn, E. (2011). Visual Language and Visual Learning (Research Brief 3). Washington DC: Science of Learning Center.

Iivari, J., \& Iivari, N. (2011). Varieties of user-centredness: an analysis of four systems development methods. Information Systems Journal, 21(2), 125-153. Retrieved from http://doi.wiley.com/10.1111/j.1365-2575.2010.00351.x

Interagency Language Roundtable. (2011a). Interagency Language Roundtable Language Skill Level Descriptions - Listening. Retrieved from http://www.govtilr.org/Skills/ ILRscale3.htm

Interagency Language Roundtable. (2011b). Interagency Language Roundtable Language Skill Level Descriptions - Speaking. Retrieved from http://www.govtilr.org/Skills/ ILRscale2.htm

Kafai, Y. B., Ching, C. C., \& Marshall, S. (1997). Children as designers of educational multimedia software. Computers \& Education, 29(2-3), 117-126. Retrieved from http:// linkinghub.elsevier.com/retrieve/pii/S0360131597000365

Kam, M., Ramachandran, D., Raghavan, A., Chiu, J., Sahni, U., \& Canny, J. (2006). Practical Considerations for Participatory Design with Rural School Children in Underdeveloped Regions : Early Reflections from the Field. Interaction Design and Children (Vol. June 79, pp. 25-32).

Knudtzon, K., Druin, A., Kaplan, N., Summers, K., Chisik, Y., Kulkarni, R., ... Bederson, B. (2003). Starting an intergenerational technology design team: a case study. Proceedings of Interaction Design and Children (pp. 51-58). Retrieved from http://dl.acm.org/ citation.cfm?id $=953545$

Korte, J. (2012). An Exploration of the Issues Involved in Eliciting Requirements from Young Deaf Children using Requirements Prototyping. Griffith University, Nathan, Australia.

Korte, J. (2017). YoungDeafDesign: A method for designing with young Deaf children. Griffith University.

Korte, J., Potter, L. E., \& Nielsen, S. (2017). The impacts of Deaf culture on designing with Deaf children. Proceedings of the 29th Australian Conference on Computer-Human Interaction (pp. 135-142). Brisbane, Australia. Retrieved from https://doi.org/ $10.1145 / 3152771.3152786$

Korte, J., Potter, L. E., \& Nielsen, S. (2017b). How design involvement impacts Deaf children. 2017 International Conference on Research and Innovation in Information Systems (ICRIIS) (pp. 1-6). Langkawi, Malaysia: IEEE.

Larsen, H. S., \& Hedvall, P.-O. (2012). Ideation and ability: When actions speak louder than words. Proceedings of the 12th Participatory Design Conference (pp. 37-40). Roskilde, Denmark. Retrieved from http://dl.acm.org/citation.cfm?id=2348157 
Masataka, N. (2000). The role of modality and input in the earliest stage of language acquisition: Studies of Japanese Sign Language. In C. Chamberlain, J. P. Morford, \& R. I. Mayberry (Eds.), Language Acquisition by Eye (pp. 3-24). Mahwah, NJ: Lawrence Erlbaum Associates.

Mitchell, T. V., \& Quittner, A. L. (1996). Multimethod study of attention and behaviour problems in hearing-impaired children. Journal of Clinical Child Psychology, 25(1), 8396.

Potter, L. E., Korte, J., \& Nielsen, S. H. (2011). Seek and Sign: An early experience of the joys and challenges of software design with young Deaf children. In Proceedings of the 23rd Australian Computer-Human Interaction Conference (pp. 257-260). Canberra, Australia: ACM.

Potter, L. E., Korte, J., \& Nielsen, S. H. (2014). Design with the Deaf: Do Deaf children need their own approach when designing technology? Proceedings of the 2014 Interaction Design and Children conference (pp. 249-252). Aarhus, Denmark: ACM.

Rabiee, P., Sloper, P., \& Beresford, B. (2005). Doing research with children and young people who do not use speech for communication. Children \& Society, 19(5), 385-396. Retrieved from http://doi.wiley.com/10.1002/chi.841

Read, J., Gregory, P., Macfarlane, S., Mcmanus, B., Gray, P., \& Patel, R. (2002). An Investigation of Participatory Design with Children - Informant, Balanced and Facilitated Design. Interaction Design and Children (pp. 53-64). Maastricht: Shaker.

Roy Morgan Research. (2016). Measuring Australia's Digital Divide: The Australian Digital Inclusion Index 2016. Retrieved from https://digitalinclusionindex.org.au/wp-content/ uploads/2016/08/Australian-Digital-Inclusion-Index-2016.pdf

Sass-Lehrer, M., \& Bodner-Johnson, B. (2003). Early intervention: Current approaches to family-centred programming. In M. Marschark \& P. E. Spencer (Eds.), Oxford Handbook of Deaf Studies, Language and Education (1st ed., pp. 65-81). Oxford: Oxford University Press.

Scaife, M., \& Rogers, Y. (1999). Kids as Informants: Telling us what we didn't know or confirming what we knew already? In A. Druin (Ed.), The Design of Children's Technology (pp. 28-50). San Francisco, USA: Morgan Kaufmann.

Scaife, M., Rogers, Y., Aldrich, F., \& Davies, M. (1997). Designing for or designing with? Informant design for interactive learning environments. In A. Druin (Ed.), Proceedings of the SIGCHI conference on Human Factors in Computing Systems (pp. 343-350). New York, New York, USA: ACM Press. Retrieved from http://portal.acm.org/citation.cfm? doid $=258549.258789$

Tan, C. Y. M. (2017). Exploring inclusive design partnerships through an IDEA Framework to support Deaf or hard of hearing Australian children in design process participation. Proceedings of the 29th Australian Conference on Computer-Human Interaction (pp. 433437). Brisbane, Australia.

Traxler, C. B. (2000). The Stanford Achievement Test, 9th Edition: National Norming and Performance Standards for Deaf and Hard-of-Hearing Students. Journal of deaf studies and deaf education, 5(4), 337-348. Retrieved from http://www.ncbi.nlm.nih.gov/pubmed/ 15454499

Vinson, T. (2009). Social Inclusion. The origins, meaning, definition and economic implications of the concept of social inclusion/exclusion. Commonwealth of Australia.

Williams, C. (2004). Emergent literacy of deaf children. Journal of deaf studies and deaf education, 9(4), 352-365. Retrieved from http://www.ncbi.nlm.nih.gov/pubmed/15314011 